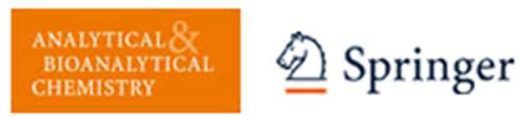

\title{
Rapid colorimetric determination of reduced and oxidized glutathione using an end point coupled enzymatic assay
}

\begin{tabular}{|r|l|}
\hline Journal: & Analytical and Bioanalytical Chemistry \\
\hline Manuscript ID: & ABC-01695-2012.R1 \\
\hline Dype of Paper: & Technical Note \\
\hline Complete List of Authors: & $\begin{array}{l}\text { Cappiello, Mario; University of Pisa, Biology } \\
\text { Peroni, Eleonora; University of Pisa, Biology } \\
\text { Lepore, Ambra; University of Pisa, Biology } \\
\text { Moschini, Roberta; University of Pisa, Biology } \\
\text { Del Corso, Antonella; University of Pisa, Biology } \\
\text { Balestri, Francesco; University of Pisa, Biology } \\
\text { Mura, Umberto; University of Pisa, Biology }\end{array}$ \\
\hline Keywords: & Bioanalytical methods, Biological samples, Enzymes \\
\hline & \multicolumn{2}{|c|}{} \\
\hline
\end{tabular}




\title{
RAPID COLORIMETRIC DETERMINATION OF REDUCED AND OXIDIZED GLUTATHIONE USING AN END-POINT COUPLED ENZYMATIC ASSAY
}

\author{
Mario Cappiello, Eleonora Peroni, Ambra Lepore, Roberta Moschini, Antonella \\ Del Corso, Francesco Balestri, Umberto Mura \\ Department of Biology, University of Pisa, Pisa, Italy \\ Corresponding author: Prof. Umberto Mura, Department of Biology, Biochemistry Unit, via S. \\ Zeno 51, 56127 Pisa, Italy; Phone: +39-050-2211451; fax: +39-050-2211460 \\ E-mail address: umura@biologia.unipi.it
}

\begin{abstract}
A simple and rapid colorimetric coupled enzymatic assay for the determination of glutathione is described. The proposed method is based on the specific reaction catalyzed by $\gamma$-glutamyltransferase, which transfers the $\gamma$-glutamyl moiety from glutathione to an acceptor, with the formation of the $\gamma$-glutamyl derivative of the acceptor and cysteinylglycine. The latter dipeptide is a substrate of leucyl aminopeptidase, which hydrolyzes cysteinylglycine to glycine and cysteine that can be easily measured spectrophotometrically. The proposed method was used to measure the content of glutathione in acid extracts of bovine lens, to follow the NADPH dependent reduction of GSSG to GSH catalyzed by the enzyme glutathione reductase and to determine the glutathione content in human astrocytoma ADF cells subjected to oxidative stress. The results obtained showed that the method can be suitably used for the determination of GSH and GSSG in different biological samples and to monitor tissue or cell redox status under different conditions. It is also applicable for following reactions involving GSH and/or GSSG.
\end{abstract}

Keywords: Glutathione, gamma-glutamyltransferase, lens, glutathione reductase, astrocytoma, oxidative stress

* Italian Patent Pending PI2011A000123, 2011 


\section{INTRODUCTION}

Glutathione (L-gamma-glutamyl-L-cysteinylglycine) is a ubiquitous low

molecular weight thiol present in high (mM range) concentrations in cells [1]. The presence of the sulfhydryl group makes glutathione a potent antioxidant, representing the main cellular defence against oxidative stress. Glutathione exerts its antioxidant action both by directly scavenging radicals and by acting as a substrate of antioxidant enzymes, such as glutathione peroxidase or glutathione S-transferases [1-2].

In addition, glutathione plays an important role in the detoxification of drugs, xenobiotics and their metabolites [3] and modulates important cell processes such as DNA and protein synthesis, amino acid transport and apoptosis [4]. Glutathione is present in cells in its reduced form (GSH) and possibly in different oxidized forms namely glutathione disulfide (GSSG) and glutathione mixed disulfides, both with low molecular weight thiols (i.e. Cys or Cys-Gly) and with proteins. In fact, the reversible S-glutathionylation of proteins under oxidative stress conditions has been proposed as a mechanism that allows the protection of proteins from irreversible oxidation [5]. Under physiological conditions, the concentration of GSH is about two orders of magnitude higher than the concentration of glutathione disulfide (GSSG). A decrease in GSH levels or an imbalance in the GSH:GSSG ratio have been found in several pathophysiological conditions, including Parkinson's disease and other neurological disorders, diabetes and immunodeficiencies [6-8].

Several methods have been developed for the measurement of GSH and GSSG in biological samples. Separative methods, based on the use of HPLC [9-15], gas chromatography [16-17] or capillary electrophoresis [18-19], are sensitive and allow the simultaneous separation and quantification of GSH and GSSG in one single step. However, to increase the sensitivity, some of the separative methods require derivatization $[9,12,15$, $]$ or the use of electrochemical $[10,11,14]$ or mass spectrometer detectors [13]. Besides requiring specific equipment, these 
methods are generally time consuming and inadequate when many samples need to be analyzed. Non-separative methods, generally based on spectrophotometric or fluorimetric measurements of products formed in the reaction of GSH with thiol-reacting agents [20-22], are characterized by a good sensitivity, low cost and simplicity; however, they lack specificity since thiols other than GSH may react with thiol reagents.

Taking advantage of a method for the measurement of $\gamma$-glutamyltransferase activity using glutathione as substrate [23], in this paper we propose a new enzyme-based end-point colorimetric method for the specific determination of GSH and oxidized glutathione. Evidence is given for the suitability of the approach to specifically measure the glutathione content in biological samples.

\section{MATERIALS AND METHODS}

\section{Materials}

Reduced glutathione, glutathione disulfide, dithiothreitol (DTT), Gly-Gly, bovine serum albumin and glutathione reductase (EC 1.8.1.7; GSR) were purchased from Sigma Chemical Co. (St. Louis, MO). Centricon 10 microconcentrators were from Millipore (Billerica, MA). DEAE cellulose (DE-52) was obtained from Whatman (Maidstone, UK). Ninhydrin came from Merck (Darmstadt, Germany). All inorganic chemicals were of reagent grade from BDH (Poole, UK).

Calf eyes were obtained from freshly slaughtered animals at the local slaughterhouse and the lenses were kept frozen until used. Human astrocytoma (ADF) cells were kindly provided by Dr. W. Malorni, Istituto Superiore di Sanità, Rome, Italy.

\section{Methods}

\section{Determination of reduced and oxidized glutathione.}

The method is based on the specific reaction catalyzed by $\gamma$-glutamyltransferase (E.C. 2.3.2.2; $\gamma$-GT), which transfers the $\gamma$-glutamyl moiety from glutathione to an 
acceptor, with the formation of the $\gamma$-glutamyl derivative of the acceptor and Cys-Gly. This dipeptide is readily hydrolized by leucyl-aminopeptidase (E.C. 3.4.11.1; LAP) [24] to form cysteine, which can then be easily measured using a colorimetric assay [25] (Scheme 1). Details on the purification of ancillary enzymes are reported in the Electronic Supplementary Material.

The standard incubation mixture ( $250 \mu \mathrm{L}$ final volume) contains $8 \mathrm{mM} \mathrm{MgCl}$, $0.2 \mathrm{mM} \mathrm{MnCl}_{2}, 40 \mathrm{mM}$ Gly-Gly, $50 \mathrm{mU} / \mathrm{mL} \gamma$-GT and $50 \mathrm{mU} / \mathrm{mL}$ LAP in $32 \mathrm{mM}$ Tris $\mathrm{HCl} \mathrm{pH} \mathrm{8.5.} \mathrm{The} \mathrm{reaction} \mathrm{is} \mathrm{started} \mathrm{by} \mathrm{the} \mathrm{addition} \mathrm{of} \mathrm{samples.} \mathrm{After} \mathrm{a} \mathrm{30-}$ min incubation at $37^{\circ} \mathrm{C}$, the reaction is stopped with the addition of $12.5 \mu \mathrm{L}$ of $100 \%(\mathrm{w} / \mathrm{v})$ trichloroacetic acid (TCA). The incubation mixture is then centrifuged at 12,000 xg for $1 \mathrm{~min}$ in a Beckman Microfuge E. The cysteine formed is evaluated spectrophotometrically. Specifically, an aliquot of $200 \mu \mathrm{L}$ of the supernatant is added to $200 \mu \mathrm{L}$ of glacial acetic acid and $200 \mu \mathrm{L}$ of a reagent, prepared by dissolving $250 \mathrm{mg}$ of ninhydrin in $10 \mathrm{~mL}$ of glacial acetic acid/4 M $\mathrm{HCl}(3: 2)$. The mixture is placed in a boiling bath for $4 \mathrm{~min}$. Under these conditions, cysteine, not other aminoacids, specifically reacts with ninhydrin to give a pink colored complex. After cooling on ice, $300 \mu \mathrm{L}$ of the mixture are diluted with $300 \mu \mathrm{L}$ of $95 \%$ ethanol and the absorbance at $560 \mathrm{~nm}$ measured. A blank obtained by adding TCA before the addition of the sample (zero time) is subtracted. In addition, a number of controls can be performed in order to take into account the presence of Cys and Cys-Gly in the samples to be analyzed. Any cysteine present in the samples can be accounted for by performing the spectrophotometric measurement without the addition of the enzymatic ancillary system. Similarly, the presence of Cys-Gly in the sample can be taken into account, once Cys is determined, by preincubating the sample in the presence of LAP alone, stopping the reaction by TCA, and then determining the produced Cys. It is worth noting however, that Cys and Cys-Gly are generally present at very low concentrations in the cell, compared with GSH and GSSG, thus in most cases they are negligible [26].

To measure the concentration of total glutathione equivalents (GSH plus GSSG plus glutathionyl-mixed disulfides), the reducing agent DTT is added to the 
standard assay mixture at a final concentration of $2 \mathrm{mM}$, before performing the GSH assay described above.

The concentration of oxidized glutathione in the presence of GSH can be evaluated by the difference between total glutathione and GSH. Oxidized glutathione can be more directly determined following the masking of GSH by preincubating the sample in the presence of $1 \mathrm{mM}$ iodoacetamide at $45^{\circ} \mathrm{C}$ for 60 min. After incubation, the sample is added to the standard incubation mixture supplemented with $2 \mathrm{mM}$ DTT for the reduction of oxidized glutathione, and the GSH level is then measured as above.

\section{Other methods}

$\gamma$-GT activity was measured as described [27]. LAP activity was measured as described [24]. One unit of enzyme activity is defined as the amount of enzyme able to generate one $\mu \mathrm{mol}$ of the product per min under the adopted assay conditions.

Protein content in the samples was measured according to Bradford [28], using bovine serum albumin as the standard reference protein.

\section{Processing of biological samples to determine the glutathione content}

Bovine lenses were suspended in approximately 5 vol of $200 \mathrm{mM} \mathrm{KCl}$ in $100 \mathrm{mM}$ $\mathrm{HCl}$ and homogenized at $4{ }^{\circ} \mathrm{C}$ in a Potter Elvehjem homogenizer. The homogenate was then centrifuged at 10,000 xg for $30 \mathrm{~min}$, ultra filtered on Centricon 10, and the protein free ultra filtrate (lens acid extract) was used for the determination of glutathione. Storage of the lens acid extracts at $-20^{\circ} \mathrm{C}$ for at least one week did not alter the concentration of glutathione.

ADF cells were cultured on plates of $10 \mathrm{~cm}$ in diameter with $10 \mathrm{~mL}$ of RPMI medium, supplemented with 10\% fetal bovine serum (v/v), $2 \mathrm{mM}$ glutamine and $50 \mathrm{mU} / \mathrm{mL}$ penicillin/streptomycin. They were then grown at $37{ }^{\circ} \mathrm{C}$ in a humidified atmosphere in the presence of $5 \% \mathrm{CO}_{2}$. Before the experiment, approximately 9 million ADF cells $\left(125000 / \mathrm{cm}^{2}\right)$ were transferred to Hank's balanced salt solution (HBSS) and subjected to oxidative 
stress through three subsequent additions every 30 minutes of $200 \mu \mathrm{M} \mathrm{H}_{2} \mathrm{O}_{2}$. After $4 \mathrm{~h}\left(\right.$ at $\left.37^{\circ} \mathrm{C}\right)$ from the last addition of $\mathrm{H}_{2} \mathrm{O}_{2}$, cells were withdrawn and lysed by the freeze/thaw procedure. The suspension was centrifuged at $10.000 \mathrm{xg}$ at $4^{\circ} \mathrm{C}$ for $30 \mathrm{~min}$ and the supernatant was referred to as cell lysate.

\section{RESULTS}

\section{Optimization of the glutathione assay conditions}

In order to determine the incubation time and the concentrations of $\gamma$-GT and LAP to be used in the assay, the time-dependent formation of cysteine from glutathione, catalyzed by the ancillary enzymes, was followed. This was done by incubating GSH at four different concentrations (from 50 to $200 \mu \mathrm{M}$ ) in the standard assay mixture in the presence of $4 \mathrm{mU} / \mathrm{mL}$ of both $\gamma$-GT and LAP. At different times, aliquots were withdrawn and assayed for cysteine concentrations (Fig. 1). After 60 min of incubation a complete transformation of GSH by the ancillary system was observed for 50, 75 and $100 \mu \mathrm{M}$ GSH, while at $200 \mu \mathrm{M}$ the trasformation was $90 \%$ complete. In order to reduce the risk of interference by samples on the ancillary system, a 12-fold increase in the concentration of both $\gamma$-GT and LAP $(50 \mathrm{mU} / \mathrm{mL})$ was adopted as standard assay conditions with 20 min of incubation. Under these conditions, a complete conversion of the standard solutions of GSH, such as those reported in Fig. 1, was observed (data not shown). To optimize the direct detection of oxidized glutathione in the presence of GSH, the reduced sulfhydryls required masking before the reduction of disulfides. Both iodoacetamide (IAM) and iodoacetic acetic (IAA), two carboxymethylating agents of thiols, were confirmed not to have interfered with the enzyme ancyllary system and thus could be used to mask GSH. The complete removal of GSH was observed after incubation in the presence of $1 \mathrm{mM} \mathrm{IAM}$ at $45^{\circ} \mathrm{C}$ for $60 \mathrm{~min}$. Under the same conditions, only 80-90\% GSH masking was observed with IAA (data not shown). As it had apparently proved to be the most efficient, IAM was adopted as a blocking agent in this study. 
When a mixture of GSH and GSSG both at $50 \mu \mathrm{M}$ was assayed for GSSG concentration after GSH masking with IAM, GSSG was completely recovered. The GSSG concentration measured by three independent assays was $50.5 \mu \mathrm{M}$, coefficient of variation (CV) $4.8 \%$. Note that an excess of IAM, which is left over after the GSH masking step, does not affect the subsequent determination of oxidized glutathione since it is rapidly removed by the excess of DTT present in the incubation mixture.

\section{Reference standard curves and assay validation}

For the construction of the reference standard curve for GSH measurements, standard GSH solutions (range $20-200 \mu \mathrm{M}$ in MilliQ grade water) were assayed in triplicate using the procedure described above. Similarly, the reference standard curve for GSSG was obtained with GSSG standard solutions (20-160 $\mu \mathrm{M}$ in MilliQ grade water) analyzed in triplicate using the above procedure. The absorbance at $560 \mathrm{~nm}$ was plotted against the standard concentrations and the parameters of the standard curves were determined by linear regression analysis. A linear relationship between absorbance at $560 \mathrm{~nm}$ and GSH concentrations was obtained (Fig. 2, top). A typical calibration curve for GSH with $20 \mu \mathrm{M}$ as the lower limit of quantitation (LLOQ) was defined by $y=0.0025 x\left(\mathrm{r}^{2}=0,996\right)$. A similar linear relationship was observed for the standard curve obtained with GSSG solutions at different concentrations (Fig. 2, bottom). A typical calibration curve for GSSG with $20 \mu \mathrm{M}$ as LLOQ was defined by $y=0.0052 x\left(\mathrm{r}^{2}=0,994\right)$. Calibration curves for GSH and GSSG were validated by determining the accuracy (\% error) and precision (\% CV) at three different concentrations (lowest, middle and highest) of the standard curves. The validation data are reported in Table 1. Both the accuracy and precision of the assays for the measurement of GSH and GSSG are well within the accepted range, which requires a CV and error $<15 \%$ except for the LLOQ, where both CV and error should not exceed $20 \%$ [29]. 


\section{Applications of the assay}

The suitability of the proposed glutathione assay method was verified following a GSH/GSSG inter-conversion reaction and by measuring GSH and oxidized glutathione equivalents in two different biological samples.

GSR catalyzed reduction of GSSG. Fig. 3 reports both the GSSG and GSH concentrations at different times, following the NADPH-dependent reduction of GSSG catalyzed by GSR. In this case, reaction mixture aliquots were assayed for total glutathione and, following the GSH masking by IAM, for GSSG. With this approach it was possible to monitor the reaction by quantifying the substrate and product, thus enabling a comparison with the direct monitoring of NADPH oxidation at $340 \mathrm{~nm}$.

Glutathione levels in bovine lens extracts. Four different lens acid extracts were analyzed in triplicate as described in the Methods, by measuring total soluble glutathione and soluble oxidized glutathione after the sulphydryls had been masked with IAM. The concentrations of GSH $($ mean \pm SD) were $0.77 \pm 0.05$, $0.75 \pm 0.07,0.78 \pm 0.09 \mathrm{mM}, 0.88 \pm 0.04$, respectively, while oxidized glutathione in all the samples was not detectable. These results account for a concentration of GSH (mean \pm SEM) in the bovine lens of $7.7 \pm 0.70 \mu \mathrm{mol} / \mathrm{g}$ wet weight of lens and are consistent with previously reported data [18]. Attempts to reveal the presence in the sample extracts of either Cys or Cys-Gly failed (data not shown), confirming the rather low levels of these thiol compounds in the lens [30], at least within the detectability limits offered by the method.

The recoveries of GSH and GSSG from lens acid extract samples supplemented with either GSH or GSSG are reported in Table 2. After spiking three different lens acid extracts with $0.500 \mathrm{mM} \mathrm{GSH}$, the mean $( \pm \mathrm{SD})$ concentrations of the added GSH was $0.502 \pm 0.020(4 \% \mathrm{CV})$. Similarly, after spiking with $0.100 \mathrm{mM}$ GSSG, the mean $( \pm \mathrm{SD})$ concentrations of the added GSSG was $0.106 \pm 0.002$ $(2 \% \mathrm{CV})$.

The intraday variability of the method was estimated on one lens extract, which was assayed twenty times using the same volume of extract $(40 \mu \mathrm{L})$ in a final assay volume of $250 \mu \mathrm{L}$. The mean $\pm \mathrm{SD}$ of GSH concentration and $\mathrm{CV}$ value 
were $0.89 \pm 0.07 \mathrm{mM}(8.9 \pm 0.75 \mu \mathrm{mol} / \mathrm{g}$ wet weight of lens tissue $)$ and $8.4 \%$, respectively. Since GSSG was not detectable in the lens acid extract, the intraday variability of the method for GSSG determination was determined in an acid lens extract sample, spiked with $0.500 \mathrm{mM}$ GSSG, which was assayed twenty times using $40 \mu \mathrm{L}$ of the spiked sample in a final assay volume of $250 \mu \mathrm{L}$. The mean \pm SD GSSG concentration and CV values were $0.520 \pm 0.047 \mathrm{mM}$ and $9.0 \%$, respectively.

Glutathione levels in human ADF cell extracts. Finally, the proposed method was applied to determine the content of intracellular glutathione in a human astrocytoma cell line, subjected to an oxidative insult by exposure to $\mathrm{H}_{2} \mathrm{O}_{2}$ (see Methods). After $\mathrm{H}_{2} \mathrm{O}_{2}$ exposure, a decrease in the intracellular reduced glutathione content was observed in the cells subjected to oxidative stress, compared with cell control incubation (Fig.4, black bars). No appreciable increase in low molecular weight oxidized forms of glutathione was observed, as it appears evident from the comparison between reduced glutathione content (Fig.4, black bar) and the glutathione content measured in the supernatant after removal of proteins (Fig.4, dashed bar). However, following the oxidative treatment, a significant increase in glutathione-mixed disulfides with proteins occurred as it appears evident from the difference between total glutathione (Fig.4, white bars) and the glutathione content measured in the supernatant after removal of proteins (Fig.4, dashed bars).

\section{DISCUSSION}

GSH and oxidized glutathione (GSSG plus GS-mixed disulfides) concentrations and their ratios are important indexes of cell redox status. Therefore, methods that can specifically and accurately measure these metabolites in biological samples may be useful in studies in which cells, tissues and organs undergo oxidative stress. Our proposal for a new specific colorimetric method to measure glutathione concentrations in biological samples is aimed at the specific determination of the glutathionyl moiety of glutathione, both in its reduced state and when reversibly linked through a disulfide bond. 
When compared to other non-separative methods based on spectrophotometric or fluorimetric measurements of products formed in the reaction of GSH with thiolreacting agents [20-22], the proposed method is less sensitive but has the advantage of a greater specificity. This is a relevant aspect in the analysis of biological samples (e.g. cell lysates) that possibly contain thiols that can interfere with thiol-reacting agents. The specificity of the two reaction steps catalyzed by the enzymatic ancillary system together with the specificity of the cysteine determination enables both GSH and oxidized glutathione to be measured. The latter is defined as the equivalent of the glutathionyl moiety present in GSSG as well as in mixed disulfides with different low molecular weight thiols (i.e. Cys and Cys-Gly) and with proteins. Clearly, when the presence of Cys and Cys-Gly and their mixed disulfides is negligible, the method is useful for specifically evaluating the redox couple GSH/GSSG. This occurs in several cell systems and conditions $[26,30]$. The presence of Cys and/or Cys-Gly, can be in any case tested by this method using appropriate controls performed without the addition of the ancillary system or by adding LAP alone.

The results of the method with different biological samples show its suitability in determining GSH and GSSG, and also in revealing different oxidized forms of glutathione (S-glutathionyl modified proteins).

When applied to follow the NADPH dependent reduction of GSSG to GSH catalyzed by the enzyme glutathione reductase, the versatility of the method can be seen as it enables the time course of the reaction to be determined by measuring both substrate and product concentrations. This may be a significant feature in cases where the spectrophotometric enzyme assay is impaired by unfavourably high optical density values of cell extracts or by enzyme activities (i.e. NADPH oxidases) that may interfere with the measurement of the oxidation of NADPH at $340 \mathrm{~nm}$.

An assay of GSH and oxidized glutathione in cell-free extracts of both bovine lens and human ADF cells, revealed how in these samples, soluble total glutathione is essentially found in a reduced state (i.e. GSH). Note that, on the basis of the results of spiked sample analysis performed on lens extracts, where added GSSG 
was quantitatively recovered, the presence of any soluble oxidized glutathione fraction should be readily detectable.

No GSSG was detected in human ADF cells even following oxidative stress induced by hydrogen peroxide. In this case, however, the observed decrease in GSH values induced by the oxidative insult is paralleled by an easily detectable increase in the equivalent of oxidized glutathione associated with reversibly Sglutathionylated high molecular weight species (i.e. S-glutathionyl- modified proteins) (Fig. 4). As mentioned above, also in oxidatively stressed ADF cells, the levels of both reduced and oxidized Cys or Cys-Gly appear to be below the threshold of detectability using this method. Thus the generation of glutathioneproteins mixed disulfides appears to be the only pathway for this cell system to react to the adopted stress conditions and can be seen as a chance to counteract irreversible cell damage [5].

In conclusion, we have developed a new, simple and fast colorimetric enzymebased end-point method to determine glutathione. The method is specific and accurate, and can be applied to follow the redox flux of glutathione in various biological samples. Work is in progress to adapt the method in order to devise a microtiter plate assay, which would allow the rapid simultaneous analysis of a large number of different samples.

\section{ACKNOWLEDGEMENTS}

We are indebted to Dr. G. Pasqualetti and Dr. R. Di Sacco (veterinary staff of Consorzio Macelli S. Miniato, Pisa) for their valuable co-operation in the bovine lens collection. Thanks are also due to Dr. Mariarosaria Loffreno for her helpful assistance in purifying $\gamma$-GT from bovine kidney.

\section{REFERENCES}

1. Meister A, Anderson ME (1983) Annu Rev Biochem 52:711-760

2. Hayes JD and McLellan LI (1999) Free Radical Res 31:273-300

3. Kaplowitz N, Aw TY, Ookhtens M (1985) Annu Rev Pharmacol Toxicol 25:715-744

4. Circu ML, Aw TY (2012) Biochim Biophys Acta 123:1767-1777

5. Del Corso A, Cappiello M, Mura U (1994) Int J Biochem 26:745-750 
6. Jha N, Jurma O, Lalli G, Liu Y, Pettus EH, Greenamyre JT, Liu RM, Forman HJ, Andersen JK (2000) J Biol Chem 275:26096-26101

7. Arnalich F, Hernanz A, López-Maderuelo D, De la Fuente M, Arnalich FM, Andres-Mateos E, Fernández-Capitán C, Montiel C (2001) Free Radic Res 35:873-884

8. Dröge W, Schulze-Osthoff K, Mihm S, Galter D, Schenk H, Eck HP, Roth S, Gmünder H (1994) FASEB J 8:1131-1138

9. Reed DJ, Babson JR, Beatty PW, Brodie AE, Ellis WW, Potter DW (1980) Anal Biochem 106:55-62

10. Richie JP Jr, Lang CA (1987) Anal Biochem 163:9-15

11. Lakritz J, Plopper CG, Buckpitt AR (1997) Anal Biochem 247:63-68

12. Giustarini D, Dalle-Donne I, Colombo R, Milzani A, Rossi R (2003) Free Radic Biol Med $35: 1365-1372$

13. Steghens JP, Flourie F, Arab K, Collombel C (2003) J Chromatogr B Anal Technol Biomed Life Sci 798:343-349

14. Vignaud C, Rakotozafy L, Falguières A, Potus J, Nicolas J (2004) J Chromatogr A 1031:125133

15. Liang SC, Wang H, Zhang ZM, Zhang HS (2005) Anal Bioanal Chem 381:1095-1100

16. Capitan P, Malmezat T, Breuillé D, Obled C. (1999) J Chromatogr B Biomed Sci Appl 732:127-135

17. Lyons J, Rauh-Pfeiffer A, Yu YM, Lu XM, Zurakowski D, Tompkins RG, Ajami AM, Young VR, Castillo L. (2000) Proc Natl Acad Sci USA 97:5071-5076

18. Cappiello M, Del Corso A, Camici M, Mura U. (1993) J Biochem Biophys Methods 26:335341

19. Havel K, Pritts K,Wielgos T (1999) J Chromatogr A 853:215-223

20. Tietze F (1969) Anal Biochem 27:502-522

21. Kosower EM, Kosower NS (1995) Methods Enzymol 251:133-148

22. Shaik IH, Mehvar R (2006) Anal Bioanal Chem 385:105-113

23. Del Corso A, Cappiello M, Buono F, Moschini R, Paolicchi A, Mura U (2006) J Biochem Biophys Methods 67:123-130

24. Cappiello M, Alterio V, Amodeo P, Del Corso A, Scaloni A, Pedone C, Moschini R, De

Donatis GM, De Simone G, Mura U (2006) Biochemistry 45:3226-3234

25. Gaitonde MK (1967) Biochem J 104:627-33

26. Giustarini D, Dalle-Donne I, Milzani A, Rossi R (2011) Mech Ageing Dev (2011) 132:141148

27. Hughey RP, Curthoys N (1976) J Biol Chem 251:8763-8770

28. Bradford, M. M. (1976) Anal Biochem 72:248-254

29. Shah VP, Midha KK, Findlay JW, Hill HM, Hulse JD, McGilveray IJ, McKay G, Miller KJ, Patnaik RN, Powell ML, Tonelli A, Viswanathan CT, Yacobi A (2000) Pharm Res 17:1551-1557 
Table 1. Validation data of the assay for measurement of GSH and GSSG. The accuracy (\% error) and precision (\% coefficient of variation, CV) at three different concentrations (lowest, middle and highest) of the standard curve were determined

\begin{tabular}{|l|r|r|r|r|r|}
\hline Compound & $\begin{array}{c}\text { Concentration } \\
(\mu \mathrm{M})\end{array}$ & $\begin{array}{c}\text { Concentration } \\
\text { measured }(\mu \mathrm{M})\end{array}$ & \% error & $\% \mathrm{CV}$ \\
\hline & 20 & & & & \\
\hline GSH & 100 & 20.9 & 4.5 & 19.8 \\
\hline GSH & 200 & 207.7 & -9.7 & 11.2 \\
\hline GSH & 20 & 16.7 & 3.8 & 6.5 \\
\hline GSSG & 80 & 76.7 & -16.5 & 7.8 \\
\hline GSSG & 160 & 138.4 & -4.1 & 12.5 \\
\hline GSSG & & & -13.5 & 7.3 \\
\hline
\end{tabular}

Table 2. Recovery of GSH and GSSG from spiked bovine lens acid extracts.

\begin{tabular}{|l|r|r|r|}
\hline Sample & Compound & $\begin{array}{c}\text { Concentration } \\
\text { added }(\mathrm{mM})\end{array}$ & $\begin{array}{c}\text { Concentration } \\
\text { measured (mM) }\end{array}$ \\
\hline Lens extract 1 & GSH & 0.500 & 0.527 \\
\hline & GSSG & 0.100 & 0.104 \\
\hline Lens extract 2 & GSH & 0.500 & 0.493 \\
\hline & GSSG & 0.100 & 0.107 \\
\hline Lens extract 3 & GSH & 0.500 & 0.485 \\
\hline & GSSG & 0.100 & 0.106 \\
\hline
\end{tabular}




\section{FIGURE LEGENDS}

Scheme 1 Principle of the method. $\gamma$-GT: $\gamma$-glutamyltransferase; LAP: leucyl-aminopeptidase

Fig. 1 Time course of cysteine production from GSH. The concentrations of cysteine formed from GSH are reported vs. the time of incubation. Four different concentrations of GSH were used: 50 $\mu \mathrm{M}$ (squares), $75 \mu \mathrm{M}$ (circles), $100 \mu \mathrm{M}$ (triangles) and $200 \mu \mathrm{M}$ (diamonds)

Fig. 2 Calibration curves for GSH and GSSG. Calibration curves for GSH (top) and GSSG (bottom) were drawn assaying standard GSH solutions (range 20-200 $\mu \mathrm{M}$ ) and standard GSSG solutions (range 20-160 $\mu \mathrm{M}$ ) as described in the Materials and Methods. Each point is the average of three measurements. Error bars represent SD; when not visible, SD is within the symbol size Fig. 3 Time course of the NADPH dependent reduction of GSSG catalyzed by glutathione reductase. GSH (circles) and GSSG (squares) concentrations were determined from the calibration curves of Fig. 2; NADPH concentration (triangles) was determined spectrophotometrically from the absorbance at $340 \mathrm{~nm}$

Fig. 4 Effect of $\mathrm{H}_{2} \mathrm{O}_{2}$ exposure on the intracellular glutathione content of ADF cells. Human ADF cells were subjected to oxidative stress as described in the Materials and Methods. Control cells were incubated in the same conditions in the absence of $\mathrm{H}_{2} \mathrm{O}_{2}$. After incubtation, cells were lysed and the lysates were divided into three aliquots. The first aliquot was immediately treated with DTT $2 \mathrm{mM}$ for 30 minutes at $37^{\circ} \mathrm{C}$ prior to protein precipitation with $0.6 \mathrm{M}$ perchloric acid (PCA); after centrifugation at 10,000 xg for 5 minutes and neutralization with $0.35 \mathrm{M} \mathrm{K}_{2} \mathrm{CO}_{3}$, GSH was measured on the supernatant (total glutathione, white bars). The second aliquot was immediately treated with PCA for deproteinization; after centrifugation and neutralization with $\mathrm{K}_{2} \mathrm{CO}_{3}$, GSH was measured on the supernatant after reduction with DTT (total glutathione minus the glutathione involved in mixed disulfides with protein, dashed bars). The third aliquot was treated in the same manner of the second aliquot except that the reduction with DTT prior of GSH measurement was omitted (reduced glutathione, black bars). Error bars represent SEM ( $\mathrm{n}=3$ ) 


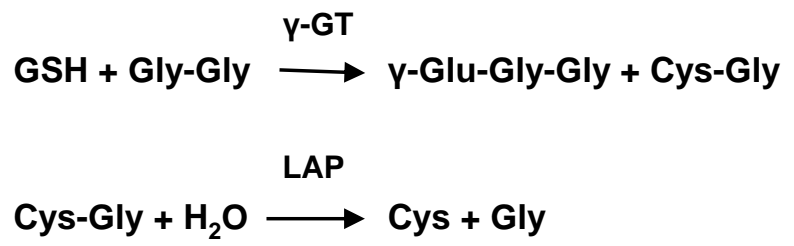




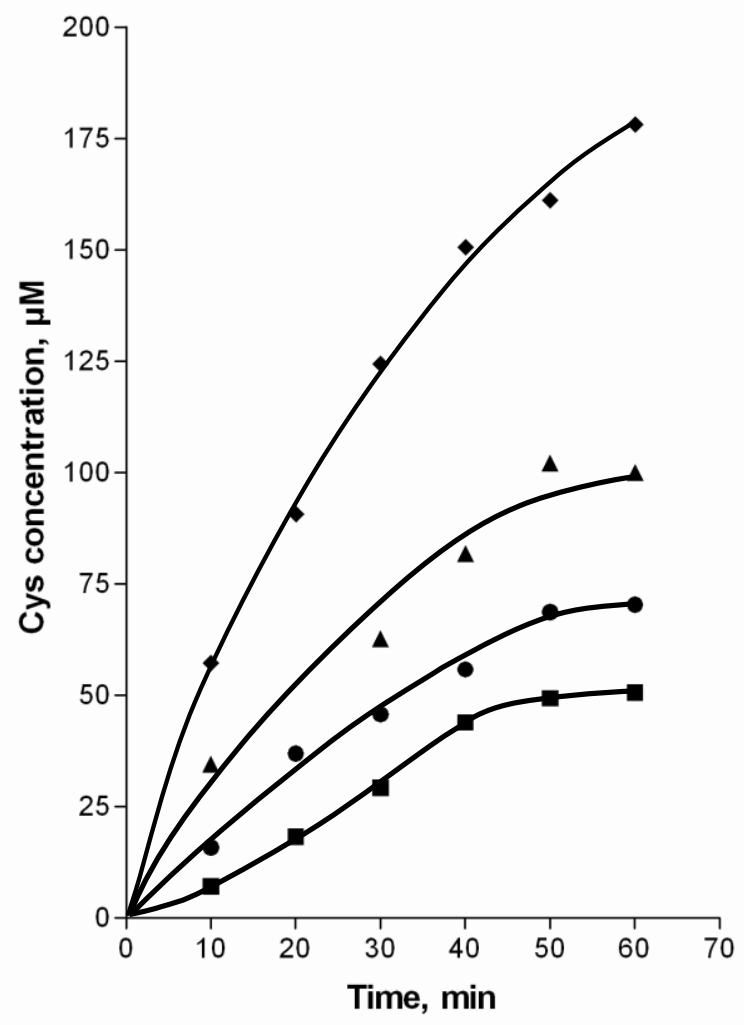




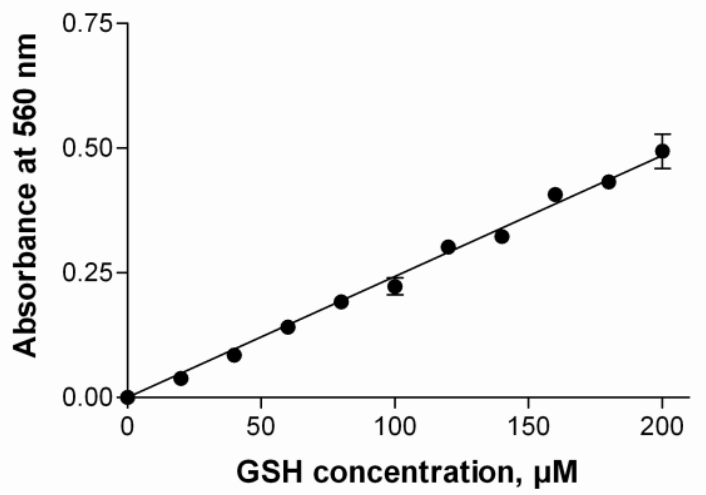

41

42

43

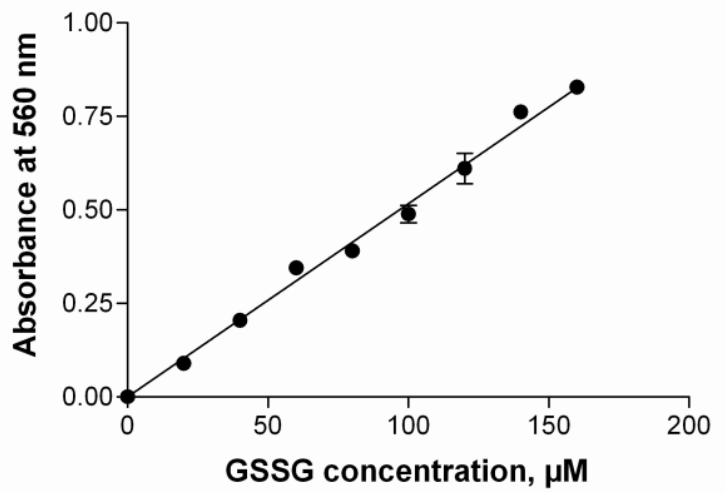




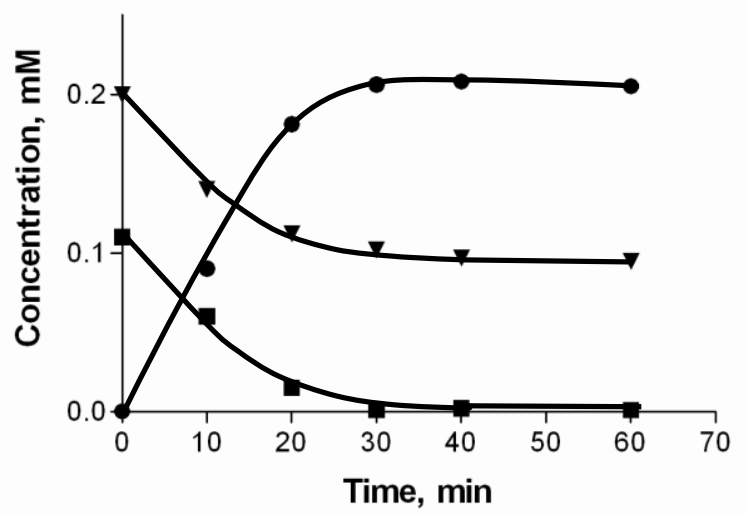


19

20

21

22

23

24

25

26

27

28

29

30

31

32

33

34

35

36

37

38

39

40

41

42

43

44

45

46

47

48

49

50

51

52

53

54

55

56

57

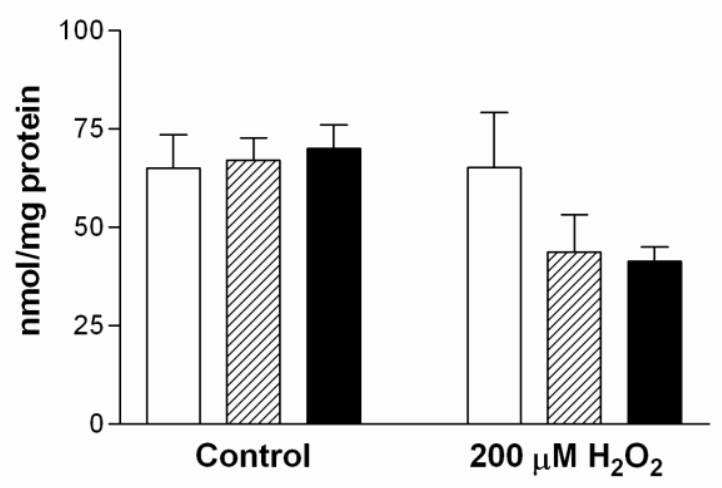

58 


\section{Purification of ancillary enzymes}

We purified in our lab the ancillary enzymes needed for the assay; the purification of both enzymes was very fast and did not require more than a couple of days. $\gamma$-GT was partially purified from bovine kidney. The kidney was weighed and homogenized in $5 \mathrm{vol}(\mathrm{w} / \mathrm{v})$ of $50 \mathrm{mM}$ Tris- $\mathrm{HCl}$ buffer ( $\mathrm{pH}$ 8.0). After stirring in an ice-cold bath for $30 \mathrm{~min}$, the suspension was centrifuged at 3,000 xg for $15 \mathrm{~min}$ at $4^{\circ} \mathrm{C}$. The supernatant was ultracentrifuged at $100,000 \mathrm{xg}$ for $60 \mathrm{~min}$. The precipitate was collected and resuspended in $50 \mathrm{mM}$ Tris-HCl buffer $(\mathrm{pH}$ 8.0) supplemented with $1 \%$ Triton $\mathrm{X}-100$. After overnight stirring at $4{ }^{\circ} \mathrm{C}$, ammonium sulphate was added to a final $50 \%$ of salt saturation. After centrifugation at 10,000 $\mathrm{x} g$ for $15 \mathrm{~min}$, the sediment was resuspended in $50 \mathrm{mM}$ Tris- $\mathrm{HCl}$ buffer $(\mathrm{pH} 8.0)$ and stored at $4{ }^{\circ} \mathrm{C}$ until use. The $\gamma$-GT preparation obtained as described above is devoid of Cys-Gly hydrolase activity and stable for at least two months.

LAP was partially purified from bovine lens. Lenses were weighed and suspended in $5 \mathrm{vol}(\mathrm{w} / \mathrm{v})$ of $10 \mathrm{mM}$ sodium phosphate buffer ( $\mathrm{pH}$ 7.0) supplemented with 5 $\mathrm{mM}$ DTT, and stirred in an ice-cold bath for $45 \mathrm{~min}$. The suspension was then centrifuged at $10,000 \mathrm{xg}$ for $40 \mathrm{~min}$ at $4^{\circ} \mathrm{C}$. The supernatant was added to $0.25 \mathrm{vol}$ of DE-52 equilibrated with $10 \mathrm{mM}$ sodium phosphate buffer $\mathrm{pH} 7.0$ supplemented with $2 \mathrm{mM}$ DTT, and stirred in an ice-cold bath. After $45 \mathrm{~min}$ the resin was filtered through a Buchner funnel, and the filtrate containing the Cys-Gly hydrolase activity was used for further purification. An equal volume of a mixture of chloroform/octanol (95:5) was added to the filtrate and the mixture was vigorously shaken at room temperature for $10 \mathrm{~min}$. The emulsion was then centrifuged at $250 \mathrm{xg}$ for $3 \mathrm{~min}$ and the supernatant, containing the enzyme activity, was collected by suction. Chloroform/octanol treatment was repeated until a little emulsion had formed. An amount of 2.5 vols of ice cold ethanol were slowly added to the supernatant resulting from the chloroform/octanol treatment. After $30 \mathrm{~min}$ stirring and subsequent centrifugation at 17,500 $\mathrm{xg}$ for $20 \mathrm{~min}$, the precipitate was resuspended in $50 \mathrm{mM}$ Tris- $\mathrm{HCl}$ buffer $(\mathrm{pH} 8.0)$ and stored at $4 \mathrm{C}$ 
until use. The LAP preparation obtained as described above is devoid of any $\gamma$ glutamyltransferase activity and stable for at least two months. 


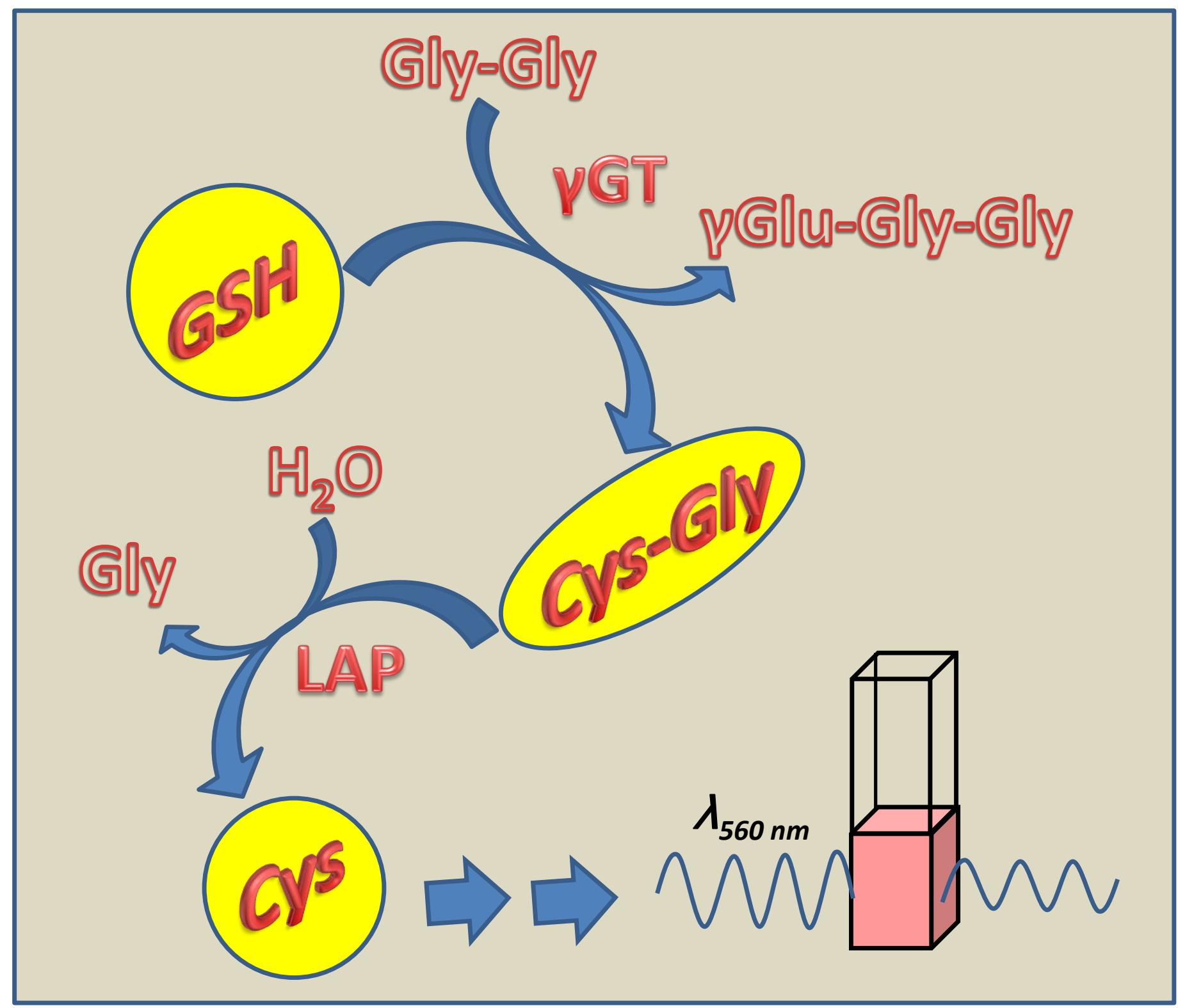

